\title{
ON THE COMPOSITION OF COMMERCIAL SAMPLES OF WHITE LEAD.
}

\author{
By G. W. W'TGNER, F.C.S., AND R. H. HARLAND, F.C.S.
}

\section{Read before the Society of Public Analysts at Burlington House, on 14th February, 1877.}

THE white lead of commerce is used chiefly for the purpose of manufacturing white paint, and it is essential that this white paint should possess two distinct although compatible properties, viz. :-1st, the power of covering or laying on to wood, or other substance, in such a way as to cover every atom of the surface painted; and secondly, opacity, or the power of hiding any colour, whether paint or other substance, which may have been beneath the paint thus being applied. Nine-tenths of the white lead manufactured in England, or indeed on the Continent, is made by what is called the Dutch method, that is by subjecting metallic lead to the action of the fumes arising from acetic acid, heated in beds of tan or other similar decomposing organic material.

In "The Analyst" of 30th September last year, we published a paper showing approximately the composition of the gases which were evolved in these stacks, but we did not on that occasion make any reference to the action which these gases have upon the metallic lead. We now propose to take a second step in the consideration of the subject, and to see the character of the compound which is produced; at another time we may consider the way in which the gares act.

Many of the older text books state that the white lead paint of commerce consists of the anhydrous meta-carbonate of lead, but this is practically disproved by the fact that the native white lead ore or cerusite is quite incapable of being ground up with oil to form a paint which shall be of any commercial value whatever. We may, therefore, leave entirely out of the question this native product, and consider only the manufactured article.

Now there are two different ways in which white lead has been manufactured, first, the Dutch process, by which at least nine-tenths of the total quantity consumed is made; and secondly, precipitation, by which a small quantity, certainly not so much as one-tenth is made.

Quoting from Watts, showing as he doubtless does, an epitome of nearly all the published statements on the subject, we find that when the precipitation process is used and an excess of carbonate of ammonia is added to a solution of lead, the anhydrous metacarbonate of lead is precipitated, while, according to Lefort, the hydrated salt, consisting of hydrated meta-carbonate of lead is thrown down, therefore, according to both these views, the precipitation consists of carbonate of lead anhydrous in the one case, and hydrated in the other case.

H. Rose, however, mentions that the precipitate always contains hydrate of lead, and this is the first time that we find any mention of this conpound occurring in any white lead, particularly in that obtained by precipitation, but it is clearly to be noted that the proportions which Rose directs for the admixture of the solutions of salts of lead and carbonate of soda, are not such as to give an excess of the alkaline base, and he further states that the composition of the precipitate thrown down was six equivalents of carbonate of lead and two equivalents of hydrate of lead + one equiralent of water. 
Rose also states that, under some conditions, which he specifically details, another compound may be obtained, consisting of five equivalents of carbonate of lead and two equivalents of hydrate of lead; and, under other conditions, another precipitate may be obtained, consisting of three equivalents of carbonate of lead and two equivalents of hydrate of lead; our experiments lead us to doubt both these results.

Watts further goes on to say that "hydrated carbonates of lead are also formed by the direct action of carbonic acid on hydrate of lead, and the compounds thus obtained differ from the precipitated carbonate in being amorphous and perfectly opaque, while the precipitated carbonate is an aggregate of minute, transparent crystalline grains."

We differ entirely from both these statements. We do not believe that the direct action of carbonic acid ever produces hydrated carbonate of lead, but, on the contrary, it produces either an admixture or a slight chemical combination of carbonate of lead and hydrate of lead, both of these compounds, however, preserving most of their original chemical properties; and when the carbonate of lead and hydrate of lead are precipitated in the proper manner, they do possess the characters, or, rather, to speak more correctly, the character, of an amorphous and opaque precipitate, and not "an aggregate of minute transparent crystalline grains."

As the result of the examination of some hundreds of samples of commercial white lead (in all nearly 1000), we must decidedly express our opinion that the material consists not of a basic carbonate, but of a mixture of a neutral carbonate, with a hydrate, and that the value of the white lead as a paint, whether it be prepared by the Dutch process or by precipitation, depends almost entirely upon the relative proportions of these two different ingredients. To put it in general terms, if lead is either by the dry or wet process converted into a hydrate, it is perfectly true that it will combine with oil, and form a kind of paint or varnish, but this paint or varnish, although it will spread over the surface of the wood or other material to be covered, will not really cover it in such a way and with such a degree of opacity as to hide the natural colour of the substance over which it is spread, but, on the contrary, it will appear like a muddy film of varnish or lacquer spread over it; or, taking the other extreme, if the compound, whether formed by the dry or wet process, consists entirely of carbonate of lead, it will form an emulsion with the oil resembling to some extent the emulsion which chalk will form with water or with syrup, and although it will possess a certain degree of opacity, it will not cover the wood or other material in such a way as to render it suitable for paint.

We have therefore come to the conclusion that the combination or mixture of the two compounds, viz. :-carbonate and hydrate of lead, is necessary in order to secure a good and servicable paint, that is the hydrate of lead must be present in order to enable the mixture to form a paint instead of an emulsion, and the carbonate of lead must be present in order to give covering power.

We will consider this subject in two ways-

1st. We have tested samples of pure carbonate of lead and have made them into paint with the greatest care, and have found that although it was possible to spread them over the surface of the substance to be painted, and to secure a certain degree of opacity, the paint never really dried or hardened, or became, in the sense a painter would use the term, a full paint, that is to say, the surface of the colour over which the paint had been 
spread was never entirely obscured, and the paint itself, even after some days of drying, was so pulverulent that ordinary washing was sufficient to remove a large portion of it.

2nd. We took commercially pure samples of hydrate of lead and we ground them up into paint in the ordinary way with linseed oil. These samples when so ground possessed comparatively no covering power, that is they spread over the substance painted, and formed a varnish-like film, similar to that which would be formed by linseed oil alone, although with a greater degree of opacity, but they did not really cover or hide the colour beneath. The chemical combination of the hydrate of lead with the linseed oil sets free a certain amount of heat, sufficient to prove that it is really a chemical combination and not a mere admixture or emulsion.

Having experimented on these substances, viz., carbonate of lead and hydrate of lead, separately, we experimented upon mixtures of them in various definite proportions. Our experiments here may be numbered by hundreds, and as the result of the whole, we have come to the conclusion that a white lead paint to be efficient, and to possess both the powers of laying on readily and easily, and by its opacity, hiding the colour beneath, must consist of an admixture of hydrate and carbonate of lead, and that this admixture must be within certain moderate limits in a definite proportion.

The results of the analysis of a very large number of the best brands of commercial white lead show that the percentage composition found, corresponds in most cases with admixtures which are between those limits, and the results of several experiments which we have made, prove to us conclusively that this is the true composition of all the best paints.

Muter in his recent book on " Pharmaceutical Chemistry," appears to have practically hit upon the true proportion, which he puts down as three equivalents of carbonate of lead and one equivalent of hydrate of lead, and this corresponds very fairly to the proportion, which we find by experience is essential to the formation of good white lead paint.

Difficulties connected with the patent law, prevent us for the present stating all the experiments which have led us to arrive at this conclusion, but we may mention one fact-if a sample of ordinary white lead paint of good quality is ground in a mortar, and dilute sulphuric acid added in small quantities from a burette, it will be found that no effervescence is produced until a sufficient quantity of sulphuric acid has been added to decompose all the linoleate of lead present, corresponding to the percentage of hydrate of lead present in the original lead; and that if the mixture be then diluted with warm water, the fatty acids correspording to the percentage of oil present, will be liberated, and will rise to the surface, and can be separated so as to determine by that means the amount of oil which has been chemically combined with the hydrate of lead. Many other experiments confirm us in this view; having formed this opinion we have made a large number of experiments to determine what proportion of hydrate of lead was most desirable, in order to form a thoroughly good white lead paint, and have come to the conclusion that this proportion should be within small limits of 25 per cent., corresponding to an actual percentage of 12.30 per cent. of carbonic acid, or somewhat less than the percentage of carbonic acid which is found in the average. In these 
commercial samples, however, the variation is very great. We have had samples containing as much as 16.33 per cent. of carbonic acid, or as little as 10.39 per cent., and in both these cases the paint, if not useless, would, at any rate, have been of the most inferior quality, and we are not surprised that some of these samples should have been returned as quite useless as paints, although they prored to be perfectly pure white lead, accepting the ordinary interpretation of the term.

The facts which we have brought forward this evening, seem to us to give ample evidence of the reasons why zinc white, carbonate of magnesia, oxyde, and other metallic carbonates and similar substances, have not been able to be used as paints with any degree of success. In the case of the white lead, a positive chemical compound has been formed, and the 75 per cent., or thereabouts, of carbonate of lead present has been dissolved in the chemical compound, and so a paint has been formed which possesses an unquestionable covering power in excess of any other compound known. Until some means can be devised by which oxyde of zinc or some other substance can be dissolved in the same way in a chemical compound, so as to form a paint possessing characters somewhat different from those of a mere emulsion, it seems useless to argue that, as regards durability or covering power, they can equal a good well manufactured sample of white lead, and, still further, while inventors will attempt, in order to increase the yield of paint from a ton of lead, to precipitate the whole of it in the form of carbonate, it is perfectly useless for them to think that that paint can possess a covering power to be compared with that of a genuine article.

Dr. Muter was very pleased Mr. Wigner confirmed him in his view, because at the time he was writing his book he kept it back six weeks on that account, as he was not satisfied with it, but after some trouble and experiments he made out that formula to be the right one, and he was very pleased to be confirmed.

Mr. Dyer asked Mr. Wigner if he had made experiments on the properties of white lead paint mixed with small quantities of baryta, or adulterated about 7 to 10 per cent. with chalk; it did not seem to him to make much difference in paint.

Mr. Harland had examined several samples of white lead manufactured by precipitating oxychloride of lead by a current of carbonic acid. This process appears to produce a very inferior paint. He examined some samples by the manufacturer's test, which was simply to mix a little ultramarine with the paint; this test certainly gave a good indication as to the body of the paint. As to Mr. Dyer's idea of adding baryta to white lead, it not only decreases its power, but makes it apt to wash off ; 5 per cent. does not hurt it much, but 10 per cent. does.

Mr. Wigner in reply to a question from Dr. Dupré, said his opinion was that white lead was not a combination of the carbonate and hydrate, but that the carbonate was left totally unchanged. They had taken 75 per cent. of lead, 25 per cent. hydrate of lead, mixed them together, ground them up with 7 per cent. of linseed oil, which made a good thick paint, too thick to lay on with a brush, but adapted for thinning in the ordinary way. If this paint is kept for any length of time the oil does not separate. The same thing occurs if we take white lead made by the ordinary Dutch method, and containing the same proportions. It seemed that the two are identical.

Dr. Dupré said that some time ago he was consulted with regard to antimony paint. It was said that there was some made in London, and in certain books it is stated as being an exceedingly good covering paint. 


\section{REVIEW. \\ THE DIGESTION AND ASSIMILATION OF FAT IN THE HUMAN BODY** By Dr. Bartlett.}

AfTER such an amusing introduction as this book has in reference to the views of the late Baron Liebig, we naturally turned to the body of the pamphlet with some misgiving. We will, however, say at once, that the substance is better than the introduction. Dr. Bartlett describes some experiments on the digestion and assimilation of fat which, if extended and verified by others, cannot fail to advance our knowledge on this subject considerably. It has been known for a long time that the pancreatic secretion has the power not only of producing an emulsion with fats, but also that of splitting them up into fatty acids and glycerine. Dr. Bartlett now adds this further property, viz: the power of splitting up the higher into lower fatty acids, and thus rendering them soluble in water. It is this latter splitting up which, according to the author, renders the fat capable of assimilating the soluble fatty acids in some way not as yet explained, during their absorption, carrying the emulsified fat along with them. Some experiments described by Dr. Bartlett certainly seem to favour this view, and, as before stated, should it prove to be the correct one, it will mark an important step in advance in our knowledge of the process of the digestion and assimilation of fats. It might be well, however, if Dr. Bartlett furnished us with some of the analytical data on which his conclusions are based, and, if he would, at the same time, state his views with somewhat less verbiage. 